\title{
Lovastatin sensitized human glioblastoma cells to TRAIL-induced apoptosis
}

\author{
David Y. L. Chan · George G. Chen · \\ Wai S. Poon · Pi C. Liu
}

Received: 18 March 2007/ Accepted: 18 September 2007/Published online: 11 October 2007

(C) The Author(s) 2007

\begin{abstract}
Synergy study with chemotherapeutic agents is a common in vitro strategy in the search for effective cancer therapy. For non-chemotherapeutic agents, efficacious synergistic effects are uncommon. Here, we have examined two non-chemotherapeutic agents for synergistic effects: lovastatin and Tumor Necrosis Factor (TNF)-related apoptosis-inducing ligand (TRAIL) for synergistic effects; on three human malignant glioblastoma cell lines, M059K, M59J, and A172. Cells treated with lovastatin plus TRAIL for $48 \mathrm{~h}$ showed $50 \%$ apoptotic cell death, whereas TRAIL alone $(1,000 \mathrm{ng} / \mathrm{ml})$ did not, suggesting that lovastatin sensitized the glioblastoma cells to TRAIL attack. Cell cycle analysis indicated that lovastatin increased $\mathrm{G}_{0^{-}}$ $\mathrm{G}_{1}$ arrest in these cells. Annexin V study demonstrated that apoptosis was the predominant mode of cell death. We conclude that the combination of lovastatin and TRAIL enhances apoptosis synergistically. Moreover, lovastatin sensitized glioblastoma cells to TRAIL, suggesting a new strategy to treat glioblastoma.
\end{abstract}

Keywords Apoptosis .

Tumor necrosis factor (TNF)-related apoptosis-inducing ligand (TRAIL) · Lovastatin · Glioblastoma

\section{Introduction}

Glioblastomas are the most common intracranial brain tumors. Its prognosis is usually poor, with survival times of

D. Y. L. Chan · G. G. Chen · W. S. Poon $(\square)$ · P. C. Liu Division of Neurosurgery, Department of Surgery, Prince of Wales Hospital, The Chinese University of Hong Kong, Shatin, Hong Kong SAR, China

e-mail: wpoon@surgery.cuhk.edu.hk less than 15 months from first diagnosis [1]. Surgical resection and chemotherapy are common treatments [2]. Despite recent advances in the understanding of the molecular mechanism of tumourogenesis, the outcome of malignant glioma remains poor [3]. Thus, new effective forms of therapy are needed.

The Tumor Necrosis Factor-Related Apoptosis-Inducing Ligand (TRAIL) [4], a member of the TNF superfamily, can bind with death receptors, DR4 and DR5 $[5,6]$ and induces apoptosis in a wide range of cancer cells without harming normal cells. The specific property of TRAIL has attracted many researchers to look for new treatments by combining it with chemotherapeutic agents such as phenoxazine derivatives [7], doxorubicin and cisplatin [8]. Such combinations have shown synergistic effects on different types of cancer cells in vitro.

Lovastatin, a 3-hydroxy-3-methlyglutaryl CoA (HMG $\mathrm{CoA}$ ) reductase inhibitor is a commonly used cholesterollowering agent for prevention of atherosclerotic cardiovascular diseases $[9,10]$. Lovastatin blocks the mevalonate pathway and reduces the formation of the downstream products, cholesterol, geranylgeranyl proteins, farnesylated [11]. Recently both in vitro and in vitro studies have found that lovastatin has antiproliferative, proapoptotic and antiinvasive properties in a wide range of cancer cell types [12]. Lovastatin is known to have an apoptotic effect on tumor cells and its combination with chemotherapeutics and cytokines often exert a synergistic effect against tumor growth [13-15]. The mechanism that leads to lovastatininduced apoptosis is not yet clear but the main event is thought to be associated with the alteration of mitochondrial stress, which releases cytochrome $\mathrm{C}$, activates procaspase cascade and finally leads to apoptotic cell death.

Escape from apoptotic regulation is one of the major characteristics of cancer [16, 17], and many successful 
anti-cancer agents induce apoptosis by damaging DNA. Unfortunately such agents may also severely affect normal cells. Given the fact that both lovastatin and TRAIL are non-chemotherapeutic agents and capable of inducing apoptosis in different types of cancer cells, it is important to determine whether the combination of these two agents would produce synergistic effects that may be lighten for a novel therapeutic application in gliomas.

We therefore hypothesized that the combination of TRAIL and lovastatin, neither of which alone has noxious effects on healthy cells, could generate a regime that was effective in killing cancer cells but caused minimal insult to normal healthy cells. In this study we report the effects of TRAIL in combination with a non-chemotherapeutic drug, lovastatin, on glioblastoma cells.

\section{Materials and methods}

\section{Reagents}

2-Methyl-1,2,3,7,8,8a-hexahdro-3,7-dimethyl-8-[2-(tetrahydro-4-hydroxy-6-oxo-2H-pyran-2-yl)ethyl]-1-naphthalenyl ester butanoic acid (Lovastatin), DL-Mevalonic acid lactone, and 3-(4,5-dimethylthiazol-2-yl)-2,5-diphenyltetrazolium bromide (MTT) were purchased from Sigma (St Louis, MO). Lovastatin was dissolved in DMSO for stock and adjusted to final concentrations using complete medium or serum free medium. Soluble Human TRAIL (Apo2L) was affinity purified from lysates of bacteria transformed with pET plasmid containing TRAIL [18]. Cellular DNA fragmentation ELISA kit (Roche, Mannheim, Germany), RNeasy kit, DNA extraction kit (Qiagen, Germany) and RT-PCR kit (Promega, Madison, WI) were used. Three primary antibodies used were as follows: rabbit polyclonal antibody to DR4 (Chemicon International, 1:1,000 dilution), rabbit polyclonal antibody to DR5 (Cell Signaling Technology, 1:1,000 dilution), and rabbit polyclonal antibody to $\beta$-tubulin (Santa Cruz Biotechnology, 1:1,000 dilution). Goat anti-rabbit secondary antibody was obtained from Santa Cruz Biotechnology.

\section{Cell culture}

Three human glioblastoma cell lines, A172, M059J, and M059K were purchased from American Type Culture Collection (Rockville, MD). The glioblastoma cells were kept in Dulbecco's modified Eagle's medium (DMEM/ F12) (GIBCO BRL, Grand Island, NY) with or without $10 \%$ fetal bovine serum, $1 \%$ penicillin and streptomycin at $37^{\circ} \mathrm{C}$ under $5 \% \mathrm{CO}_{2}$. Media were changed every 3 days.
Measurement of cell viability

We measured cell viability using the MTT assay. MTT is a water-soluble tetrazolium salt that is metabolized by viable cells to a colored, water-insoluble formazan salt. Thus the salt allows cell viability measurements. In short, $1 \times 10^{4}$ cells were cultured in the serum free DMEM/F12 medium in the presence of lovastatin with or without TRAIL in a 96 well microtiter plate for designated time periods. The medium was aspirated and $100 \mu \mathrm{l}$ MTT $(0.5 \mathrm{mg} / \mathrm{ml}$ in PBS) were added to each well and the cells incubated for $3 \mathrm{~h}$. After MTT medium was aspirated, the cells were solubilized in $200 \mu \mathrm{l}$ DMSO. The optical density of each sample at $570 \mathrm{~nm}$ (reference $630 \mathrm{~nm}$ ) was measured using a microplate reader. The optical density of the media was proportional to the degree of viable cells.

Cell cycle analysis

Propidium iodide (PI) staining and flow cytometry were used to determine the stage of the cell cycle. Cells were treated with $20 \mu \mathrm{M}$ lovastatin for $48 \mathrm{~h}$ at $37^{\circ} \mathrm{C}$ and the control cells were treated with normal medium (DMSO) or serum free medium (DMSO). $2 \times 10^{6}$ treated cells were washed with $5 \mathrm{ml}$ PBS and then were trypsinized at $37^{\circ} \mathrm{C}$ for $5-10 \mathrm{~min}$. Cells were spun down and washed with $5 \mathrm{ml}$ PBS. Finally cells were resuspended in $500 \mu \mathrm{l}$ PBS and fixed with $4.5 \mathrm{ml} 70 \%$ Ethanol with gentle vortexing. Cells were allowed to sit in $-20^{\circ} \mathrm{C}$ for overnight. Fixed cells were spun down and washed with $5 \mathrm{ml}$ PBS, and then cells were resuspended in $500 \mu \mathrm{l} \mathrm{PI}(2 \mu \mathrm{g} /$ $\mathrm{ml}) /$ Triton X-100 (0.1\% v/v) staining solution with RNase A $(200 \mu \mathrm{g} / \mathrm{ml})$ in dark and analyzed by a flow cytometer. The staining solution was purchased from Chemicon (Temecula, CA).

Apoptosis assay

Apoptotic cells were determined by two methods, Annexin-V and PI stained cells by flow cytometry and DNA fragmentation assay. During apoptosis, translocation of phosphatidylserine from inner membrane to outer membrane is a common phenomenon. Cells were stained with Annexin $\mathrm{V}$ for analysis of phosphoserine inversion, which was considered to be a sensitive marker of apoptosis. Using an Annexin V-FITC apoptosis detection kit (Molecular Probe Inc, Eugene, OR), the levels of binding of Annexin V and staining with PI were measured for the detection of early and late apoptosis respectively. All of the procedures were preformed under manufacturer's guidelines. Cells were treated with lovastatin or/and TRAIL for 
$48 \mathrm{~h}$ and then stained with Annexin-V and PI. Viable cells were recognized as negative for both Annexin-V and PI; early apoptotic events were positive for Annexin-V but negative for PI staining. Late apoptotic events were positive to both Annexin V and PI. Necrotic cells were positive for PI staining only.

DNA fragmentation determination, was carried out with the ELISA assay kit. After cells $\left(1 \times 10^{4}\right)$ were treated with lovastatin and/or TRAIL for $48 \mathrm{~h}$, DNA fragmentation was detected using 96 wells microplate reader.

\section{RT-PCR}

Total RNA was isolated using Qiagen RNeasy extraction kit and performed according to the manufacturer's protocol. Total RNA $(5 \mu \mathrm{g})$ was reversely transcribed using Promega RT-PCR kit and thermal program was set at $42^{\circ} \mathrm{C}$ for $15 \mathrm{~min}$ and $95^{\circ} \mathrm{C}$ for $5 \mathrm{~min}$. PCR reaction was performed using the following primers, which have previously been tested successfully: TRAIL-R1, 5'-CTG AGC AAC GCA GAC TCG CTG TCC AC- $3^{\prime}$ and $5^{\prime}$-TCC AAG GAC ACG GCA GAG CCT GTG CCA T-3'; TRAIL-R2, 5'GCC TCA TGG ACA ATG AGA TAA AGG TGG CT-3' and $5^{\prime}$-CCA AAT CTC AAA GTA CGC ACA AAC GG3'; TRAIL-R3, 5'-GAA GAA TTT GGT GCC AAT GCC ACT G-3' and 5'-CTC TTG GAC TTG GCT GGG AGA TGT G-3'; TRAIL-R4, 5'-CTT TTC CGG CGG CGT TCA TGT CCT TC-3' and $5^{\prime}$-GTT TCT TCC AGG CTG CTT CCC TTT GTA G- $3^{\prime}$. The thermal program was set up as one cycle at $94^{\circ} \mathrm{C}$ for $5 \mathrm{~min}, 30$ cycles at $94^{\circ} \mathrm{C}$ for $1 \mathrm{~min}$, $55^{\circ} \mathrm{C}$ for $1 \mathrm{~min}, 72^{\circ} \mathrm{C}$ for $2 \mathrm{~min}$, and one cycle at $72^{\circ} \mathrm{C}$ for $5 \mathrm{~min}$. PCR products were resolved and visualized on a $2 \%$ agarose gel stained with ethidium bromide.

\section{Western blot analysis}

Western blot was performed according to previous description [19, 20]. Briefly, after $2 \times 10^{6}$ cells were treated for $48 \mathrm{~h}$, total protein was isolated and reacted with the relevant antibodies. The probed proteins were visualized using the enhanced chemiluminescence Western blotting detection system (ECL Western Blotting Detection, Amersham Biosciences).

\section{Statistics}

The statistical significance was analyzed using one-way ANOVA analysis and Student's $t$-test. All statistical work was carried out using the SPSS software for Windows (Release 11.0.1, Chicago, IL). Differences were considered to be significant when $P<0.05$.

\section{Results}

Cell viability measured by MTT assay

We first examined the anti-proliferation effect of TRAIL on three glioblastoma cell lines. M059K and M059J glioblastoma cells were resistant to TRAIL-induced cell death and remained $100 \%$ cell viable following treatment in both normal and serum free conditions (Fig. 1a, b). Only A172 showed minor cell death after TRAIL treatment $(22 \%$, Fig. 1a).

Synergistic effects by TRAIL and lovastatin were then examined. A172, M059J, and M059K glioblastoma cells were incubated in $1,5,20$, and $40 \mu \mathrm{M}$ lovastatin alone or together with $500 \mathrm{ng} / \mathrm{ml}$ TRAIL for $48 \mathrm{~h}$. In A172 glioblastoma cells, 5, 20, and $40 \mu \mathrm{M}$ lovastatin with $500 \mathrm{ng} /$ $\mathrm{ml}$ TRAIL promoted significant cell death when compared with lovastatin control (Fig. 2a). 5, 20 and $40 \mu \mathrm{M}$ lovastatin alone induced $50 \%, 60 \%$ and $76 \%$ of cell death respectively, however in the presence of $500 \mathrm{ng} / \mathrm{ml}$ TRAIL, lovastatin induced $78 \%, 94 \%$, and $92 \%$ of cell death respectively. $1,5,20$, and $40 \mu \mathrm{M}$ lovastatin with $500 \mathrm{ng} / \mathrm{ml}$ TRAIL also synergistically promoted cell death in M059J and M059K. In M059J cells, 1, 5, 20 and
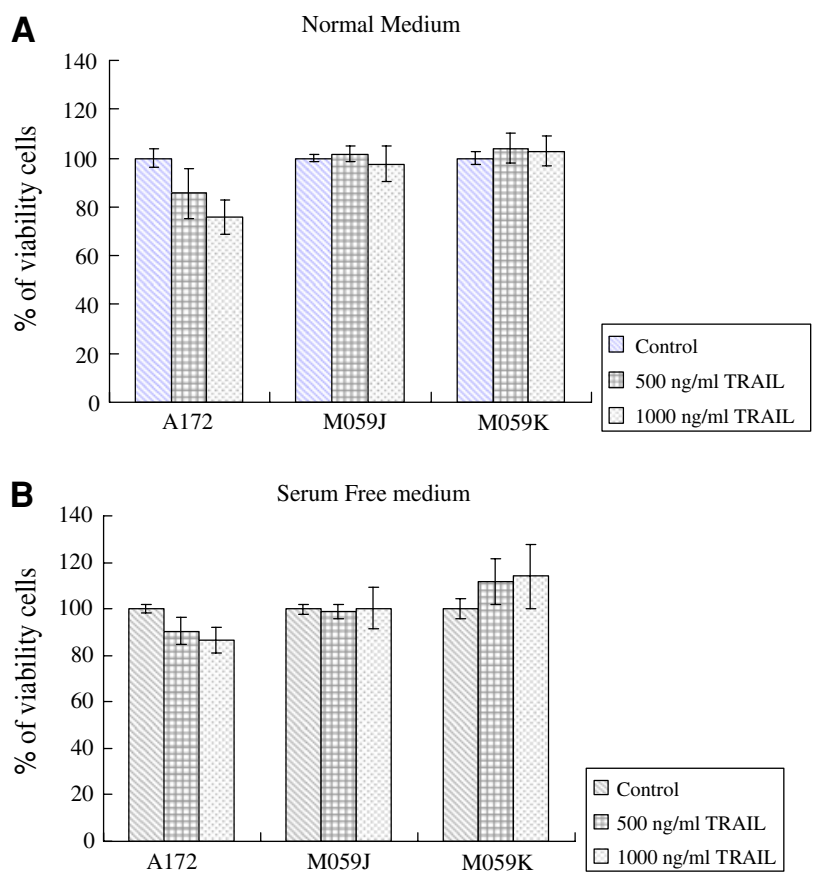

Fig. 1 Anti-proliferation effects on glioblastoma cell lines A172, M059K, and M059J. MTT assays were preformed after $48 \mathrm{~h}$ incubation time treated with $0,500,1,000 \mathrm{ng} / \mathrm{ml}$ TRAIL in normal medium (a) or serum free medium (b). A172 subjected to minor TRAIL-induced cell death while M059J and M059K cells were resistant to TRAIL. Same trend of data were obtained in both normal medium and serum free condition. Experiment set were repeated at least three times with triplicate wells for each condition (mean $\pm \mathrm{SD}$ ) 
$40 \mu \mathrm{M}$ lovastatin alone caused $40 \%, 55 \%, 40 \%$ and $60 \%$ cell death whereas in the presence of $500 \mathrm{ng} / \mathrm{ml}$ TRAIL, lovastatin induced $83 \%, 94 \%, 95 \%$ and $95 \%$ cell death respectively (Fig. 2b). There were 26\%, 51\%, 58\%, and $71 \%$ cell death induced by $1,5,20$, and $40 \mu \mathrm{M}$ lovastatin alone in M059K, in the presence of $500 \mathrm{ng} / \mathrm{ml}$ TRAIL, lovastatin at all concentration tested caused about $98 \%$ of cell death (Fig. 2c). Collectively the combination of TRAIL and lovastatin was much more effective than lovastatin alone in the induction of cell death in all three glioblastoma cells tested and the result indicated that there was a synergistic effect when TRAIL and lovastatin were used together.

\section{Cell cycle determination by PI staining}

Propidium iodide staining and flow cytometry were used to determine the degree of cell synchronization by $20 \mu \mathrm{M}$ lovastatin. Cells were incubated with normal serum medium, serum free medium and $20 \mu \mathrm{M}$ lovastatin with normal serum medium for $48 \mathrm{~h}$. PI-stained cells were analyzed using flow cytometry to quantify cells in certain cell cycle stages. A significant increase in cell population at G0/G1 phase was observed when the cells were treated with $20 \mu \mathrm{M}$ lovastatin indicating that lovastatin was able to arrest the cells at G0/G1 stage. G0/G1 cell population was also increased by serum free medium conditions (positive control) and the increase reached a significant level except in M059J cells (Fig. 3).

Apoptosis is the major mode of cell death

In order to determine the mode of cell death induced by lovastatin and TRAIL, Annexin V and PI staining was employed for this purpose. Cells were incubated with 5 or $20 \mu \mathrm{M}$ of lovastatin in the presence or absence of $500 \mathrm{ng} /$ $\mathrm{ml}$ TRAIL for $48 \mathrm{~h}$. The percentage of cell death of glioblastoma cells treated with both lovastatin and TRAIL was significantly higher than that with either agent alone (Fig. 4a, b and c). A172 glioblastoma cells were vulnerable to TRAIL induced apoptosis (Fig. 4a) but significantly more apoptotic cells were observed following treatment with both TRAIL and lovastatin $(P<0.005)$ (Fig. 4a). TRAIL was able to induce apoptosis in $50 \%$ of A172 glioblastoma cells. However, TRAIL in combination with 5 and $20 \mu \mathrm{M}$ could induce apoptosis in approximately $67 \%$ and $74 \%$ cells respectively, indicating a synergistic effect occurred. Similarly, a significant synergistic effect was also observed in M059K and M059J cells $(P<0.005)$ (Fig. 4b, c), with up to nearly a 10 -fold increase in apoptotic cells. $5 \mu \mathrm{M}$
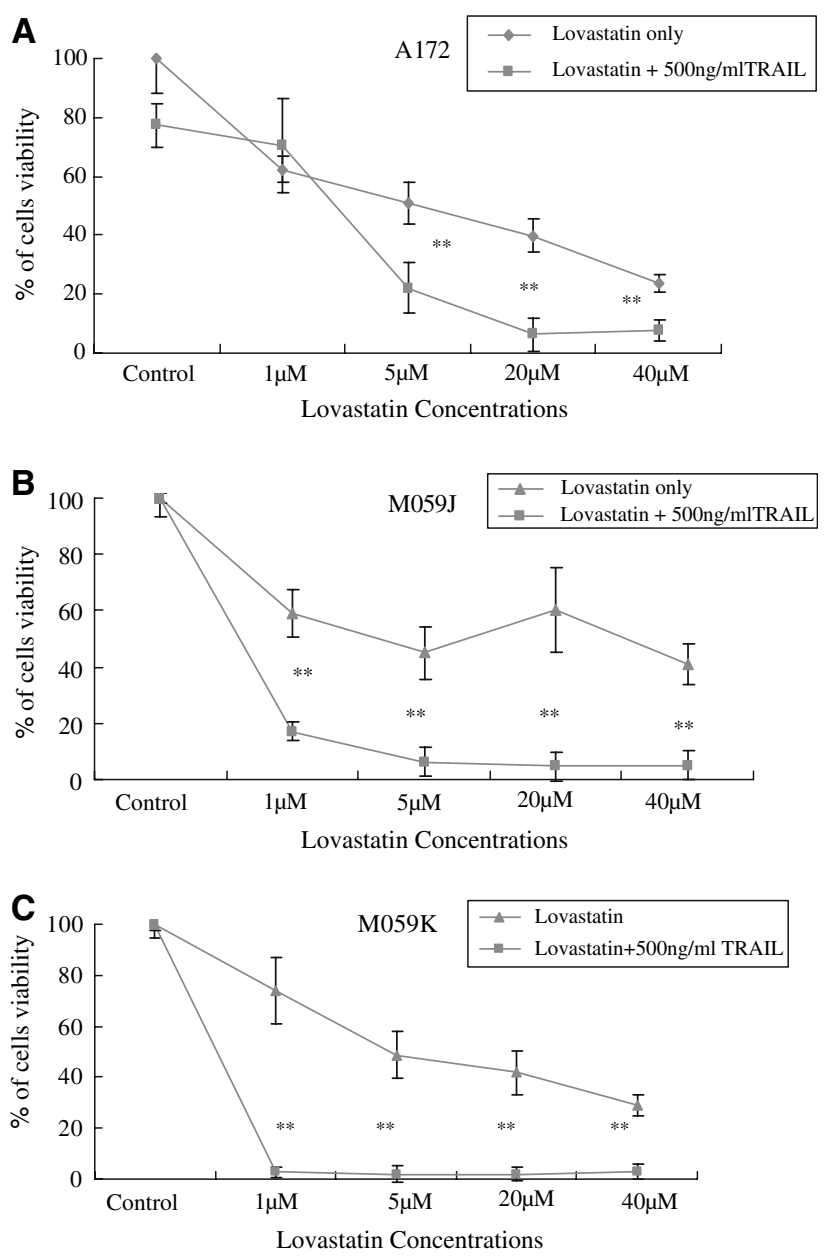

Fig. 2 Synergistic anti-proliferation effects on glioblastoma cell lines A172, M059J, and M059K. Glioblastoma cells were treated with 0, 5, 20 and $40 \mu \mathrm{M}$ lovastatin alone or $0 \mu \mathrm{M}$ lovastatin plus $500 \mathrm{ng} / \mathrm{ml}$ TRAIL, $5 \mu \mathrm{M}$ lovastatin plus $500 \mathrm{ng} / \mathrm{ml}$ TRAIL, $20 \mu \mathrm{M}$ lovastatin plus $500 \mathrm{ng} / \mathrm{ml}$ TRAIL and $40 \mu \mathrm{M}$ lovastatin plus $500 \mathrm{ng} / \mathrm{ml}$ TRAIL for $48 \mathrm{~h}$. Percentage of viable glioblastoma cells showed synergistic anti-proliferation effects by combined the two agents. In A172 glioblastoma cells (a), $500 \mathrm{ng} / \mathrm{ml}$ TRAIL with 5,20 and $40 \mu \mathrm{M}$ lovastatin induced cell death significantly when compared with lovastatin only groups. In M059J (b) and M059K (c), $500 \mathrm{ng} / \mathrm{ml}$ TRAIL with $1,5,20$ and $40 \mu \mathrm{M}$ lovastatin induced cell death significantly when compared with lovastatin only groups. ANOVA were used for statistics analysis and $* P<0.05$, $* * P<0.01$. Experimental set were repeated for at least three times with triplicate wells for each condition (mean $\pm \mathrm{SD}$ )

lovastatin only induced apoptosis in 5.3\% and 2.3\% M059J and M059K respectively, which were not different from the control (without any treatment). $5 \mu \mathrm{M}$ lovastatin plus $500 \mathrm{ng} / \mathrm{ml}$ TRAIL dramatically increased apoptotic cells to $47.8 \%$ and $61.4 \%$ in $\mathrm{M} 059 \mathrm{~J}$ and $\mathrm{M} 059 \mathrm{~K}$ respectively. M059J cells, which lack of DNA-dependent protein kinase expression [21], were less vulnerable to the two agents, implying that DNA-dependent protein kinase may play a role in apoptosis induced by TRAIL and lovastatin. 


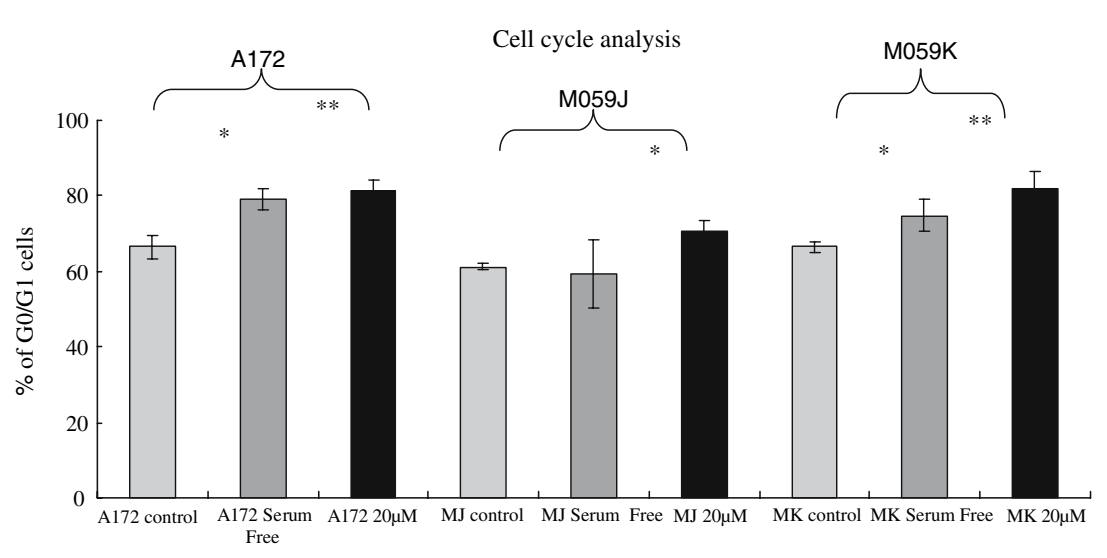

Fig. 3 Lovastatin-induced glioblastoma cells arrested in $\mathrm{G}_{0}-\mathrm{G}_{1}$ Phase. Propidium Iodide staining for cell cycle analysis were performed after glioblastoma cells were treated with normal medium without lovastatin, serum free medium without lovastatin and $20 \mu \mathrm{M}$ lovastatin for $48 \mathrm{~h}$. Serum free condition was used as a positive control which is commonly known to induce cell arrest in $\mathrm{G}_{0}-\mathrm{G}_{1}$

DNA fragmentation in glioblastoma cells

DNA fragmentation is one of the hallmarks when cells undergo apoptosis. We performed ELISA assay to confirm DNA fragmentation was induced in the cells treated with both lovastatin and TRAIL. A synergistic effect on DNA fragmentation by both agents was demonstrated in all three cell lines tested (Fig. 5a, b and c). The level of DNA fragmentation was increased in treated A172 glioblastoma cells, but it was only statistically significant in the cells treated with TRAIL plus $20 \mu \mathrm{M}$ lovastatin. In M059J and M059K cells, however, there was a dramatic elevation of DNA fragmentation in a dose-dependent manner when both of the agents were applied. This observation supports the argument that the cell death induced by the two agents was apoptotic and that both agents were able to function in a synergistic manner.

The expression of TRAIL receptors in glioblastoma cells

Resistance to cell death induced by TRAIL may be adapted by an altered level of TRAIL receptors. TRAIL-R3 (DcR1) and TRAIL-R4 (DcR2) are known to attenuate TRAILinduced apoptosis whereas TRAIL-R1 (DR4) and TRAILR2 (DR5) promote TRAIL-induced apoptosis [5]. The effect of lovastatin treatment on the TRAIL receptors was not determined. RT-PCR was performed to investigate the expression profiles on three glioblastoma cell lines tested. Cells were treated with normal serum medium, serum free medium, serum medium with 5 or $20 \mu \mathrm{M}$ lovastatin for $48 \mathrm{~h}$. TRAIL-R3 and R4 were not detected in all conditions phase. Serum free condition and lovastatin increased $\mathrm{G}_{0}-\mathrm{G}_{1}$ cell arrest in all glioblastoma cells and reached significant level (except serum free condition in M059J). ANOVA were used for statistics analysis and $* P<0.05,{ }^{*} * P<0.01$. Experimental set were repeated for at least three times with triplicate wells for each condition $($ mean $\pm \mathrm{SD})$

and cell types tested. TRAIL-R1 was only detected on M059J cells with serum free medium or lovastatin (Fig. 6 a). TRAIL-R2 was expressed on all cell types of cells with or without lovastatin and its level was not significantly different between lovastatin-treated cells and the controls. Therefore, the expression of TRAIL-R2 did not contribute to the lovastatin-induced cell death in glioblastoma cells tested.

After we tested the mRNA expression of TRAIL receptors on glioblastoma cells, the further investigation was performed to determine the active protein expression of TRAIL-R1 and matured TRAIL-R2 by Western blot. The result showed that the protein expression profiles of TRAIL-R1 and TRAIL-R2 were found in three glioblastoma cells with or without lovastatin, suggesting the protein of these two receptors was underwent post-translational modifications. The significantly differences were only found on the TRAIL-R1 expression of M059K cells with $20 \mu \mathrm{M}$ lovastatin $(P=0.05)$ and the expression of TRAIL-R2 in A172 cells with lovastatin $(P<0.01)$ (Fig. 7).

\section{Discussion}

Malignant glioblastoma is one of the major causes of brain tumors morbidity. Aggressive infiltration in the CNS ultimately leads to death in nearly all cases [2]. Malignant glioblastoma carries with aberrant biological and biochemical properties including several activating mutations that can lead to chemotherapeutics resistance [22]. Targeting apoptotic signaling machinery is thought to be a promising alternative for glioblastoma treatment [23]. The 
Fig. 4 The synergistic apoptotic effects were quantified by flow cytometry using Annexin V and PI staining. Glioblastoma cells were treated with DMSO (Control), $5 \mu \mathrm{M}$ lovastatin, $20 \mu \mathrm{M}$ lovastatin, $500 \mathrm{ng} / \mathrm{ml}$ TRAIL, $5 \mu \mathrm{M}$ lovastatin plus $500 \mathrm{ng} / \mathrm{ml}$ TRAIL and $20 \mu \mathrm{M}$ lovastatin plus $500 \mathrm{ng} / \mathrm{ml}$ TRAIL for $48 \mathrm{~h}$. Then cells were stained with Annexin V and PI to determine percentage of apoptotic cell death using flow cytometry. Synergistic apoptotic effects were observed in three glioblastoma cell lines A172 (a), M059J (b) and M059K (c), reached significant level. The portion of apoptotic cell death was indicated in lowright quarter of the flowcytometry scatter plot and the trend of apoptotic cells between groups. ANOVA were used for statistics analysis and $* P<0.05, * * P<0.01$ (compared to control group), ${ }^{+} P<0.05,{ }^{++} P<0.01$ (compared to TRAIL only group). Experimental set were repeated for at least three times (mean $\pm \mathrm{SD}$ )

\section{A}

A172
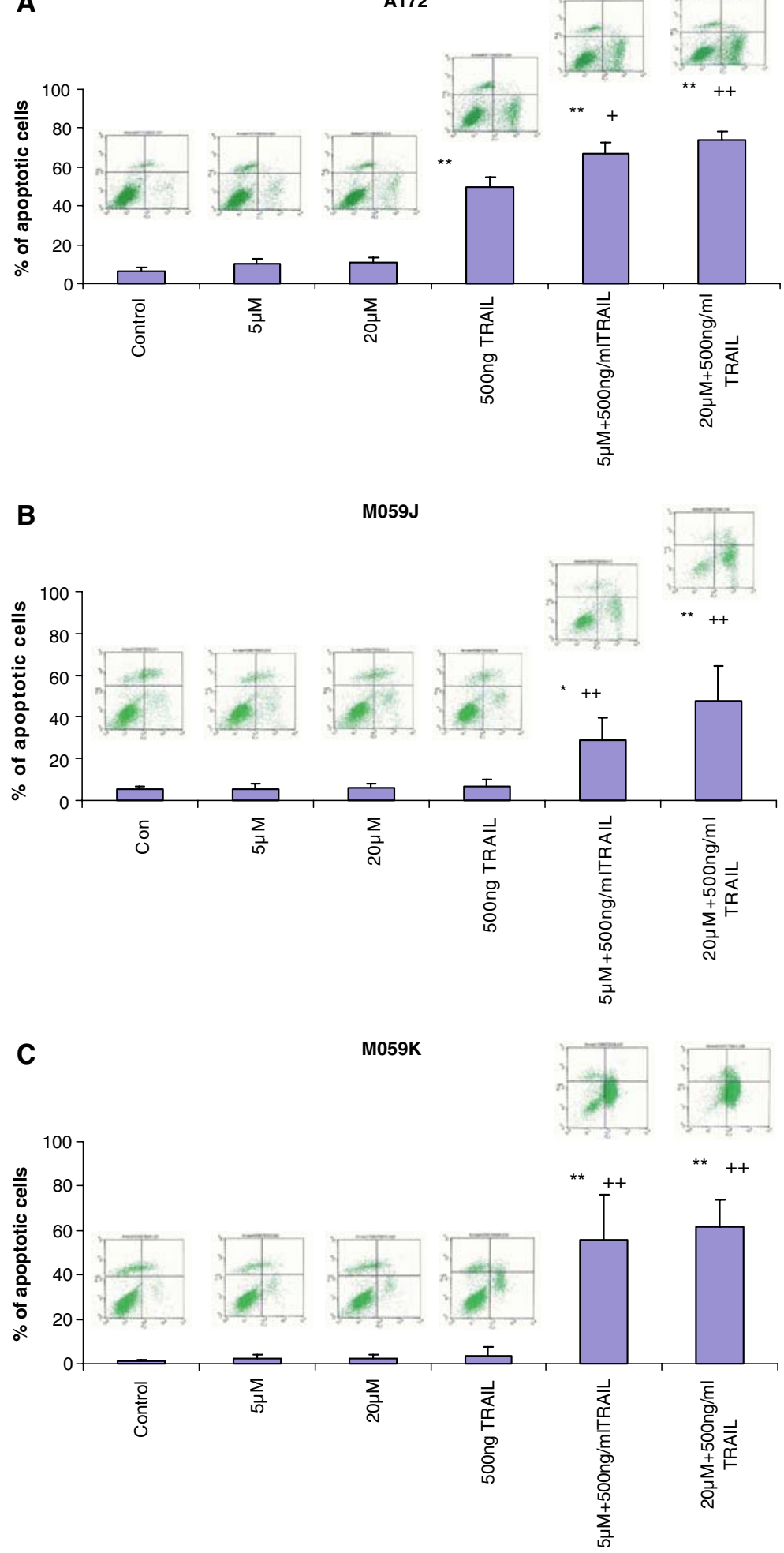

preliminary data presented in this report indicate that lovastatin, a blood cholesterol lowering medicine, sensitizes glioblastoma cells to TRAIL-mediated apoptosis. Earlier reports show statin-induced cell death through a mitochondrial-mediate pathway (intrinsic pathway) that is closely related to the Bcl-2 family protein Bid and activation of caspase 8, 9 and 3 [24-27]. However, the mechanism for statin activation of caspase 8 remains unknown because caspase 8 is normally activated by receptor-mediated signals, such as Fas ligand and TRAIL [5]. 
Fig. 5 DNA fragmentation was detected in combination of lovastatin and TRAIL. Same treatment in apoptotic cell staining was preformed for DNA fragmentation ELISA detection. Significant level of DNA fragmentation was detected in all glioblastoma cells when combined with lovastatin and TRAIL. ANOVA were used for statistics analysis and $* P<0.05, * * P<0.01$ (compared to control group), ${ }^{+} P<0.05,{ }^{++} P<0.01$ (compared to TRAIL only group). Experimental set were repeated for at least three times $($ mean $\pm \mathrm{SD})$
A

A172
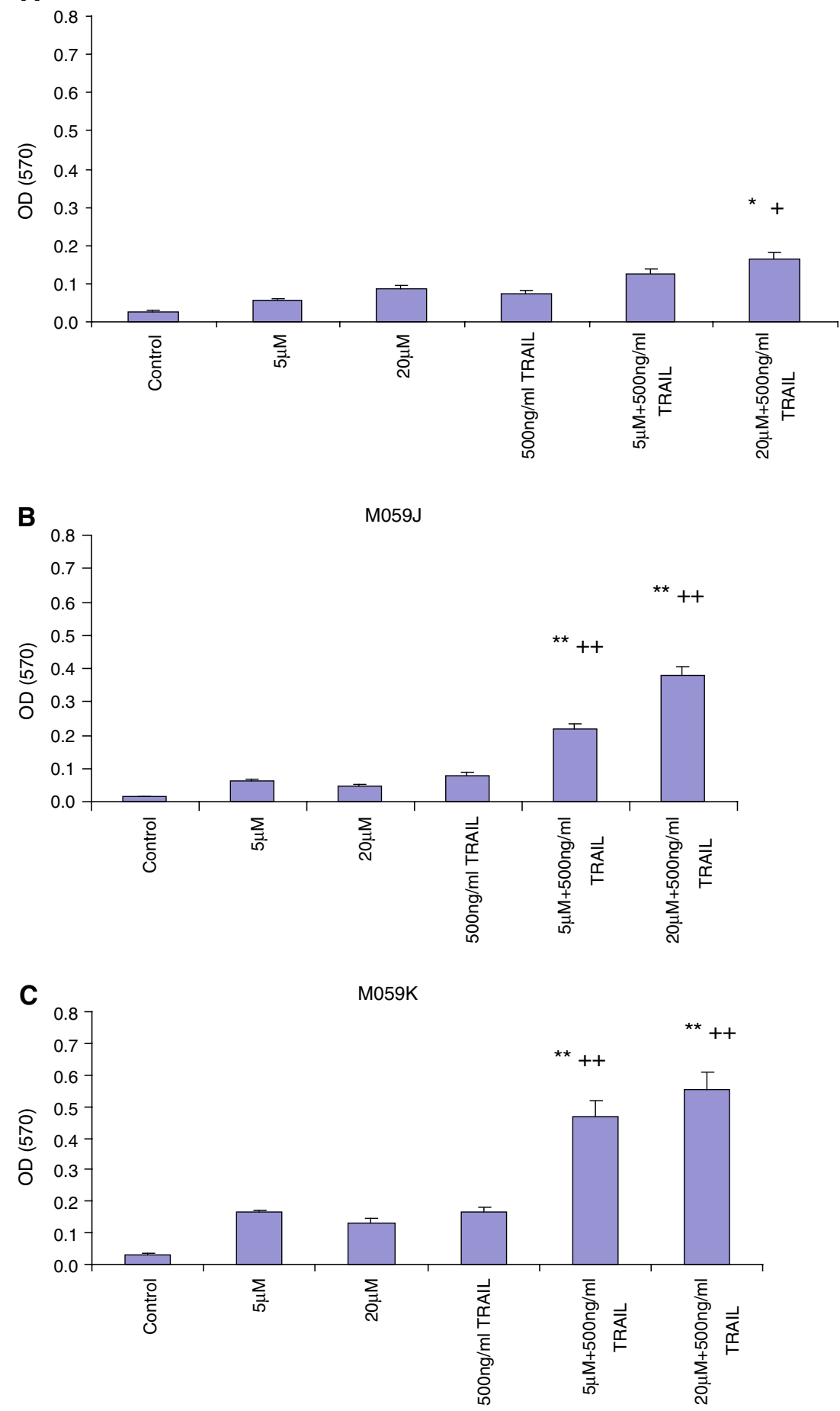

Lovastatin has been found to enhance TRAIL-induced cytotoxicity in a synergistic manner in glioblastoma cells. We demonstrated a synergistic effect produced by the combination of lovastatin and TRAIL on glioblastoma cells. Lovastatin was found to sensitize the cells to cell death induced by TRAIL. The mode of cell death induced by both agents in combination was apoptosis, as demonstrated by two different methods, Annexin V and PI staining and DNA fragmentation assay. We also demonstrated that two of the glioblastoma cell lines tested were resistant to TRAIL induced apoptosis. From this we inferred that lovastatin not only sensitized these glioblastoma cells through its effects on the TRAIL receptor pathway but also triggered an unknown mechanism: Lovastatin served as a cytostatic agent and turned on an unknown mechanism to support TRAIL-induced apoptosis 
Fig. 6 The expression of TRAIL receptor mRNA in glioblastoma cells. The cells were treated with normal serum medium, serum free medium, 5 and $20 \mu \mathrm{M}$ lovastatin with normal serum medium. At the end of the treatment, RNA was isolated for the detection of TRAIL-R1 (DR4) (a) and TRAIL-R2 (DR5) (b) by RTPCR
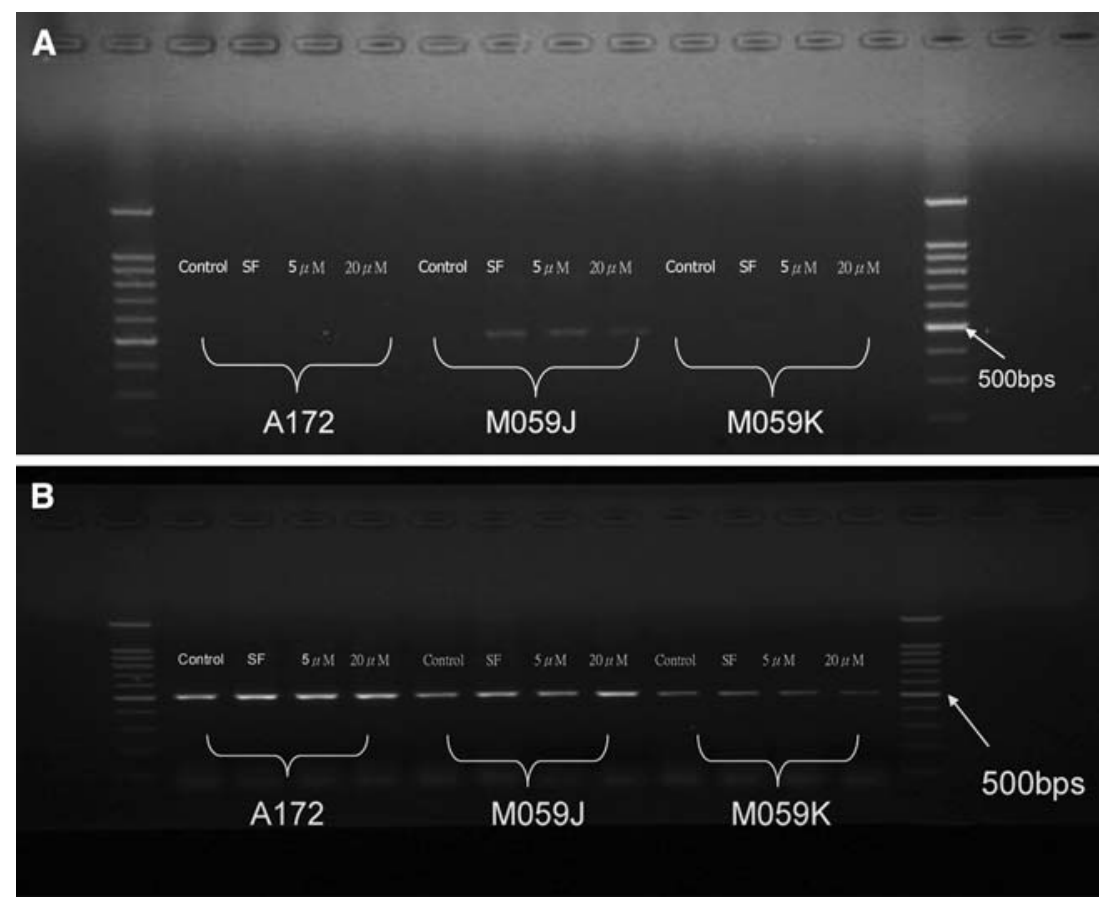

in these glioblastoma cells. It has been shown that colon and lung tumor cells arrested in $\mathrm{G}_{0}-\mathrm{G}_{1}$ stages are vulnerable to TRAIL-induced cell death [28]. However, our $\mathrm{G}_{0-}$ $\mathrm{G}_{1}$ arrested glioblastoma cell lines remained resistant to TRAIL-induced cell death in the serum free control. Our finding suggests that a combination of TRAIL and lovastatin together may form a new treatment for glioblastoma multiforme.

The mechanism by which lovastatin sensitizes glioblastoma cells to TRAIL induced-apoptosis remains unknown. In human glioblastoma, lovastatin has been shown to induce or to enhance apoptosis by altering a number of apoptotic molecules. For example, it can induce apoptosis or downregulate cell proliferation by targeting Ras in primary cultured human glioblastoma cells [29] and increase pro-apoptotic Bim in U87 and U251 glioblastoma cells [30]. Lovastatin has also been shown to downregulate RhoA and increase iNOS in T98G and A172 glioblastoma cells [31]. Additionally, Lovastatin may induce apoptosis by increasing p21 and the apoptosis induced can be prevented by the overexpression of Bcl-2 [32], suggesting a mitochondrial-related apoptosis. It is noted that this study by Schmidt et al. fails to document that lovastatin can enhance death receptor (CD95)-mediated apoptosis in glioblastoma cells LN-18, LN-229, LN-308 and T98G [32]. The result from our study indicate that lovastatin in combination with TRAIL can synergistically induce apoptosis in A172, M059K and M059J glioblastoma cells. The apoptosis induced is associated with $G_{0}-G_{1}$ arrest but not with pro-apoptotic Bid (data not shown). It is well known that TRAIL-induced apoptosis takes place via a death receptor-mediated pathway [5, 33].

Our study showed that TRAIL-R1 mRNA expressed in M059J but was hardly detected in the other two cell lines. However, TRAIL-R1 protein was detectable in all three cell lines, suggesting that the TRAIL-R1 was modified by a post-translational mechanism in the cells tested. The level of TRAIL-R1 protein was higher in M059K cells treated with $20 \mu \mathrm{M}$ of lovastatin. However, such an elevation of TRAIL-R1 is unlikely to be responsible for apoptosis induced by lovastatin because the apoptotic rate between M059K was not different from the other cell lines. TRAIL$\mathrm{R} 2$ can be detected at both protein and RNA levels. The level of TRAIL-2 mRNA was not different in the cells treated with lovastatin but its protein level was much higher in A178 cells treated with either 5 or $10 \mathrm{mM}$ lovastatin, the result of which indicated that TRAIL-R2 was modified by a post-translational mechanism in A172 cells. It is noted that the base level of TRAIL-2 in A172 cells does not differ from other two cell lines tested. Therefore, it is unlikely that TRAIL-2 could count for the relatively higher sensitivity of A172 cells to TRAIL stimulation than the other two cell lines. All three cell lines underwent a similar level of cell death when they were treated by lovastatin. Therefore, the contribution of lovastatin-induced TRAIL-2 protein to the cell death in A172 cells seems to be minimal. Such results appear to be in line with a study using mevastatin, a similar HMG-CoA reductase inhibitor. Mevastatin can significantly induce apoptosis of myeloma cells in a pathway independent of death receptors including 
Fig. 7 The expression of TRAIL-R1 (DR4) and TRAILR2 (DR5) proteins in glioblastoma cells. The cells were treated with normal serum medium, serum free medium, 5 and $20 \mu \mathrm{M}$ lovastatin with normal serum medium for $48 \mathrm{~h}$. At the end of the treatment, proteins were isolated for the detection of TRAIL-R1 $(\mathbf{a}, \mathbf{b})$ and TRAIL-R2 (c, d) by Western blot. Representative Western blots were shown (a, c). The target bands were scanned and normalized to $\beta$ tubulin. The index of densities was calculated $(\mathbf{b}, \mathbf{d})$. $* P=0.05, * * P<0.01$
A

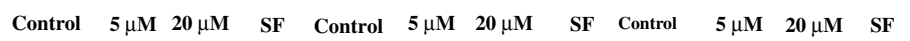
DR 4

$\beta$-Tubulin

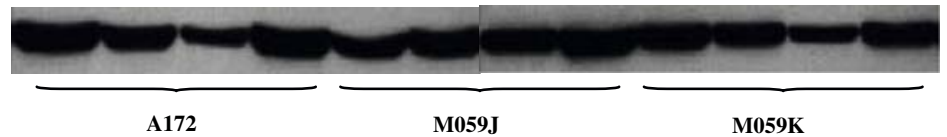

B

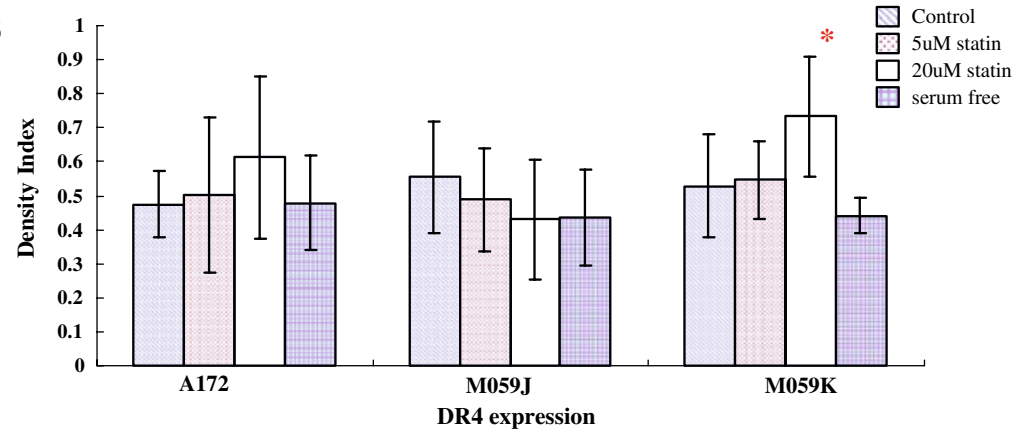

C

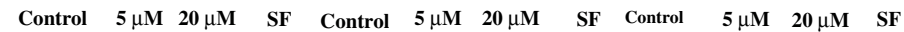
DR 5 $\beta$-Tubulin

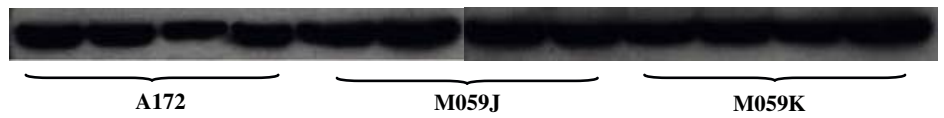

\section{D}

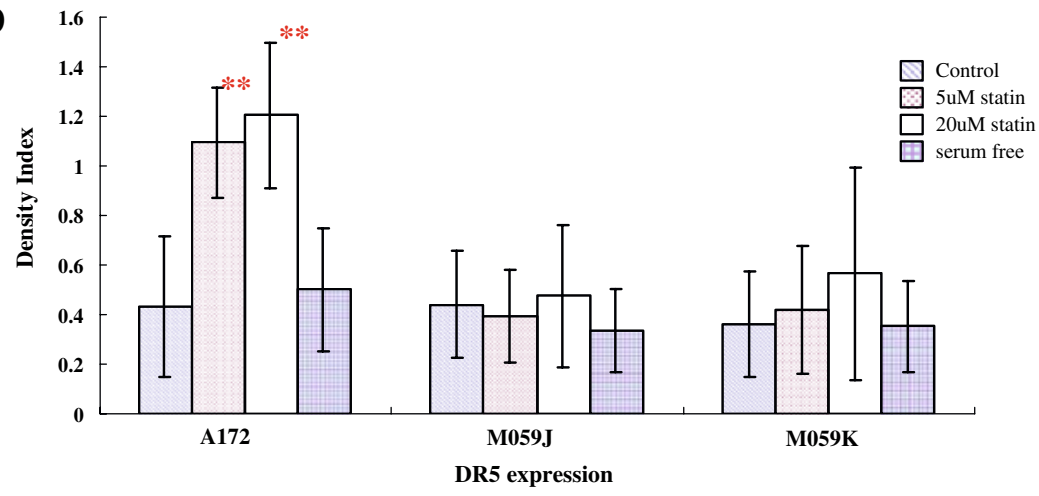

TRAIL-R2 [34]. Nevertheless, further quantitative tests are needed in glioblastoma cells to verify the result obtained.

Apoptosis induced by lovastatin is generally considered to be via the mitochondrial-mediated pathway [30; 32]. It is possible for both pathways to talk to each other to amplify apoptotic signals and this is indeed a case for TRAIL, since TRAIL is capable of inducing either mitochondrial-independent or -dependent apoptotic pathways in some types of cells $[17,33]$. The Bid is a molecule functions as a bridge that links death receptor- and mitochondrial-mediated pathways. Therefore, without involvement of Bid, apoptosis induced by TRAIL and lovastatin in combination in the present study seem to be separately mediated by these two pathways. However, considering the fact that two out of three glioblastoma cells tested are insensitive to TRAIL treatment but they become responsive in the presence of lovastatin, it can be hypothesized that lovastatin treatment may remove an unknown inhibitory factor(s) that overcomes the TRAIL-mediated pathway or that lovastatin may "wake up" an activator(s) that normally remains in a resting condition. One of inhibitory factors known to involve TRAIL-mediated pathways is its decoys, TRAILR3 and TRAIL-R4 [5, 33]. However, it can be seem from our study that this inhibitory factor(s), if any, should not be the decoys TRAIL-R3 and TRAIL-R4 since both are not detectable in the cells tested. One possible explanation for this synergistic effect is the activation of caspase 8 , an initiator caspase in death receptor-mediated pathways. Lovastatin has been shown to enhance caspase 8 activity [35]. It is possible that caspase- 8 is the activator factors waken up by lovastatin. Whatever it is, the mechanism accounting for the synergistic effect of TRAIL and 
lovastatin against glioblastoma cells in the present study is complicated and remains to be uncovered.

Mevalonate is a critical component of a complex biochemical pathway and its products are vital for a variety of important cellular functions including cell signaling, protein synthesis, and cell cycle regulation [11]. Little is known about the molecular events leading to apoptosis of cancer cells due to lovastatin exposure. It is likely that apoptosis is abrogated by mevalonate and GGPP and is partially reversed by FPP [12].

Our results also reinforced the conclusion of our previous study, that DNA-dependent protein kinase (DNA-PK) plays an important role in cell apoptosis. M059J cells that lack of DNA-PK activity are resistant not only to total cell death but also apoptosis [19, 20]. Experts disagree over the functions of DNA-PK in cell regulation. DNA-PK has been reported to promote cell death by interacting with telomeres, whereas other reports suggest that DNA-PK protects cells from cell death via caspase-independent or p53 independent pathways. The reason for this paradoxical finding remains unknown.

This study demonstrated a synergistic interaction between lovastatin and TRAIL, but the mechanisms of action by which lovastatin sensitized glioblastoma cells remains unknown. Our results are in agreement with the concept of combined cancer therapeutic action via both intrinsic and extrinsic apoptotic cell death pathways. This combination of non-chemotherapeutic agents, TRAIL and lovastatin, may offer a potential regime for glioblastoma treatment.

Acknowledgements We thank Mr. Billy C. S. Leung and Miss SukYing Chun for their technical assistance in the fluorescence-activated cell sorter analysis and cell cultures.

\section{References}

1. Grossman SA, Batara JF (2004) Current management of glioblastoma multiforme. Semin Oncol 31:635-644

2. DeAngelis LM (2001) Brain tumors. N Engl J Med 344:114-123

3. Reardon DA, Wen PY (2006) Therapeutic advances in the treatment of glioblastoma: rationale and potential role of targeted agents. Oncologist 11:152-164

4. Wiley SR, Schooley K, Smolak PJ, Din WS, Huang CP, Nicholl JK, Sutherland GR, Smith TD, Rauch C, Smith CA et al (1995) Identification and characterization of a new member of the TNF family that induces apoptosis. Immunity 3:673-682

5. Ashkenazi A, Dixit VM (1998) Death receptors: signaling and modulation. Science 281:1305-1308

6. Kimberley FC, Screaton GR (2004) Following a TRAIL: update on a ligand and its five receptors. Cell Res 14:359-372

7. Kato S, Shirato K, Imaizumi K, Toyota H, Mizuguchi J, Odawara M, Che XF, Akiyama S, Abe A, Tomoda A (2006) Anticancer effects of phenoxazine derivatives combined with tumor necrosis factor-related apoptosis-inducing ligand on pancreatic cancer cell lines, KLM-1 and MIA-PaCa-2. Oncol Rep 15:843-848
8. Mirandola P, Sponzilli I, Gobbi G, Marmiroli S, Rinaldi L, Binazzi R, Piccari GG, Ramazzotti G, Gaboardi GC, Cocco L, Vitale M (2006) Anticancer agents sensitize osteosarcoma cells to TNF-related apoptosis-inducing ligand downmodulating IAP family proteins. Int J Oncol 28:127-133

9. Grundy SM (1988) HMG-CoA reductase inhibitors for treatment of hypercholesterolemia. N Engl J Med 319:24-33

10. Ness GC, Zhao Z, Lopez D (1996) Inhibitors of cholesterol biosynthesis increase hepatic low-density lipoprotein receptor protein degradation. Arch Biochem Biophys 325:242-248

11. Goldstein JL, Brown MS (1990) Regulation of the mevalonate pathway. Nature 343:425-430

12. Chan KK, Oza AM, Siu LL (2003) The statins as anticancer agents. Clin Cancer Res 9:10-19

13. Holstein SA, Hohl RJ (2001) Synergistic interaction of lovastatin and paclitaxel in human cancer cells. Mol Cancer Ther 1:141-149

14. Werner M, Sacher J, Hohenegger M (2004) Mutual amplification of apoptosis by statin-induced mitochondrial stress and doxorubicin toxicity in human rhabdomyosarcoma cells. Br J Pharmacol 143:715-724

15. Knapp AC, Huang J, Starling G, Kiener PA (2000) Inhibitors of HMG-CoA reductase sensitize human smooth muscle cells to Fas-ligand and cytokine-induced cell death. Atherosclerosis 152:217-227

16. Hanahan D, Weinberg RA (2000) The hallmarks of cancer. Cell 100:57-70

17. Reed JC (2000) Mechanisms of apoptosis. Am J Pathol 157:1415-1430

18. Chinnaiyan AM, Prasad U, Shankar S, Hamstra DA, Shanaiah M, Chenevert TL, Ross BD, Rehemtulla A (2000) Combined effect of tumor necrosis factor-related apoptosis-inducing ligand and ionizing radiation in breast cancer therapy. Proc Natl Acad Sci U S A 97:1754-1759

19. Chen GG, Sin FL, Leung BC, Ng HK, Poon WS (2005) Glioblastoma cells deficient in DNA-dependent protein kinase are resistant to cell death. J Cell Physiol 203:127-132

20. Chen GG, Sin FL, Leung BC, Ng HK, Poon WS (2005) Differential role of hydrogen peroxide and staurosporine in induction of cell death in glioblastoma cells lacking DNA-dependent protein kinase. Apoptosis 10:185-192

21. Allalunis-Turner MJ, Barron GM, Day RS III, Dobler KD, Mirzayans R (1993) Isolation of two cell lines from a human malignant glioma specimen differing in sensitivity to radiation and chemotherapeutic drugs. Radiat Res 134:349-354

22. Kelley TW, Tubbs RR, Prayson RA (2005) Molecular diagnostic techniques for the clinical evaluation of gliomas. Diagn Mol Pathol 14:1-8

23. Rich JN, Bigner DD (2004) Development of novel targeted therapies in the treatment of malignant glioma. Nat Rev Drug Discov 3:430-446

24. Cafforio P, Dammacco F, Gernone A, Silvestris F (2005) Statins activate the mitochondrial pathway of apoptosis in human lymphoblasts and myeloma cells. Carcinogenesis 26:883-891

25. Shibata MA, Ito Y, Morimoto J, Otsuki Y (2004) Lovastatin inhibits tumor growth and lung metastasis in mouse mammary carcinoma model: a p53-independent mitochondrial-mediated apoptotic mechanism. Carcinogenesis 25:1887-1898

26. Chapman-Shimshoni D, Yuklea M, Radnay J, Shapiro H, Lishner M (2003) Simvastatin induces apoptosis of B-CLL cells by activation of mitochondrial caspase 9. Exp Hematol 31:779-783

27. Janosi J, Sebestyen A, Bocsi J, Barna G, Nagy K, Valyi-Nagy I, Kopper L (2004) Mevastatin induced apoptosis in U266 human myeloma cell line. Magy Onkol 48:333-337

28. Jin Z, Dicker DT, El Deiry WS (2002) Enhanced sensitivity of G1 arrested human cancer cells suggests a novel therapeutic strategy 
using a combination of simvastatin and TRAIL. Cell Cycle 1:8289

29. Bouterfa HL, Sattelmeyer V, Czub S, Vordermark D, Roosen K, Tonn JC (2000) Inhibition of Ras farnesylation by lovastatin leads to downregulation of proliferation and migration in primary cultured human glioblastoma cells. Anticancer Res 20:2761-2771

30. Jiang Z, Zheng X, Lytle RA, Higashikubo R, Rich KM (2004) Lovastatin-induced up-regulation of the BH3-only protein, Bim, and cell death in glioblastoma cells. J Neurochem 89:168-178

31. Rattan R, Giri S, Singh AK, Singh I (2003) Rho A negatively regulates cytokine-mediated inducible nitric oxide synthase expression in brain-derived transformed cell lines: negative regulation of IKKalpha. Free Radic Biol Med 35:1037-1050
32. Schmidt F, Groscurth P, Kermer M, Dichgans J, Weller M (2001) Lovastatin and phenylacetate induce apoptosis, but not differentiation, in human malignant glioma cells. Acta Neuropathol 101:217-224

33. Bouralexis S, Findlay DM, Evdokiou A (2005) Death to the bad guys: targeting cancer via Apo2L/TRAIL. Apoptosis 10:35-51

34. Janosi J, Sebestyen A, Bocsi J, Barna G, Nagy K, Valyi-Nagy I, Kopper L (2004) Mevastatin-induced apoptosis and growth suppression in U266 myeloma cells. Anticancer Res 24:1817-1822

35. Knight MJ, Riffkin CD, Ekert PG, Ashley DM, Hawkins CJ (2004) Caspase-8 levels affect necessity for mitochondrial amplification in death ligand-induced glioma cell apoptosis. Mol Carcinog 39:173-182 